\title{
COMPARATIVE ANALYSIS OF INTER SIMPLE SEQUENCE REPEATS AND SIMPLE SEQUENCE REPEATS MARKERS: GENETIC ANALYSIS OF DESCHAMPSIA CESPITOSA POPULATIONS GROWING IN METAL CONTAMINATED REGIONS IN CANADA
}

\author{
${ }^{1,2}$ Nkongolo, K.K., ${ }^{1,3}$ S. Gervais, ${ }^{1,2}$ P. Michael and ${ }^{1,4}$ Y. Zhou \\ ${ }^{1}$ Department of Biology, \\ ${ }^{2}$ Biomolecular Sciences Program, Laurentian University, Sudbury, \\ Ontario, P3E 2C6, Canada \\ ${ }^{3}$ Northern Ontario School of Medicine, Sudbury, Ontario, \\ ${ }^{4}$ Department of Psychiatry, University of Toronto, \\ 250 College Street, 8th Floor, Toronto, Ontario, M5T 1R8, Canada
}

Received 2014-02-14; Revised 2014-03-13; Accepted 2014-04-08

\begin{abstract}
Comparative studies conducted on the genetic variation of metal-tolerant populations and their non-metaltolerant counterparts have been performed on numerous species using isozyme markers. Analysis of genetic differences among plant populations growing in heavy metal-contaminated and uncontaminated regions are limited. The main objectives of the present study were to compare ISSR and microsatellite markers in assessing genetic variation in D. cespitosa populations that colonized metal-contaminated and uncontaminated regions in Northern Ontario, Canada. Total genomic DNA from D. cespitosa samples were amplified with ISSR and SSR primers using optimized PCR conditions. The level of polymorphic loci varies from 46 to $74 \%$ for ISSR analysis. The level of observed heterozygosity was moderate to high ranging from 0.44 to 0.68 for the SSR primers used. But no significant difference in genetic variation levels was detected between metal contaminated and uncontaminated sites with SSR markers. There was a significant reduction of polymorphic loci in samples from highly metal-contaminated areas of the Cobalt region compared to the reference sites based on ISSR analysis. Use of a combination of different marker systems is recommended to analyse genetic variation in plant populations.
\end{abstract}

Keywords: ISSR, SSR (Microsatellite), Deschampsia cespitosa, Genetic Variation, Northern Ontario

\section{INTRODUCTION}

Genetic diversity comprises the entire complement of genetic characteristics associated with a population or a species. It is crucial for maintaining healthy populations that are able to respond favourably and adapt to changes or disturbances in the environment (Bourret et al., 2007). Contaminants in the environment may have an array of effects on the genetic diversity of a population. If tolerance to the adverse environmental condition increases as a function of individual heterozygosity and/or if the Corresponding Author: Nkongolo, K.K., Biomolecular Sciences Pro. contaminant is a mutagen, genetic variation within the affected population will remain elevated and may increase. On the other hand, genetic variation may be lost as a result of population bottleneck in response to the severe selective pressures acting upon the population and/or the migration of a small subset of individuals into the contaminated areas resulting in a founder effect (Bourret et al., 2007).

Comparative studies conducted on the genetic variation of metal-tolerant populations and their nonmetal-tolerant counterparts have been performed on numerous species. Results derived from the analysis of 
morphological traits and enzymatic variations of Agrostis stolonifera and Silene paradoxa suggest that, despite founder effect and selection, the recently established metal-tolerant populations often maintain a high level of variation and appear to be at least as variable as the non-tolerant founding populations (Mengoni et al., 2000). However, other metal-tolerant species such as Armeria maritime demonstrate a marked reduction of genetic diversity (Deng et al., 2007).

Previous studies on the genetic diversity of Deschampsia cespitosa, based on allozyme and RAPD (random fragment length polymorphism) analysis, have indicated to some extent the reduced genetic diversity of populations located on contaminated soil (Bush and Barrett, 1993; Nkongolo et al., 2001). However, allozymes have been described as limited by the amount of polymorphism, the number of scorable loci and detection of diversity is exclusive to coding regions (Mosseler et al., 1992), while RAPD markers are limited by their dominant nature and technical inconsistency (Qian et al., 2001). Random Fragment Length Polymorphism (RFLP) markers, though extremely powerful for comparative mapping approaches, are quite time consuming, laborious, require large amounts of DNA and species-specific probes (Nkongolo et al., 2001). Inter-Simple Sequence Repeat (ISSR) technique has grown in popularity since its introduction in 1994 and has superseded the RAPD method (Zietkiewicz et al., 1994). Studies on the genetic diversity of Eleusine have indicated ISSRs as a superior marker technique relative to RFLP and RAPD. Also, it has been recognized as the marker of choice for assessments of genetic diversity in cocoa, gymnosperms and fungi (Reddy et al., 2002).

On the other hand, numerous comparative analyses have documented a substantial advantage of microsatellite markers over other molecular systems. For instance, studies on soybean (Akkaya et al., 1992), rice (Wu and Tanksley, 1993), Arabidopsis (Bell and Ecker, 1994), Elymus caninus (Sun et al., 1999), Pinus spp. (Mehes et al., 2009), Sesam umindicum L. (Kumar and Sharma, 2011) and Phoenix dactyliferaL. Hamza et al. (2013) conclude that microsatellite loci are more polymorphic than previously attempted methods.

The main objectives of the present study were to compare ISSR and microsatellite markers in assessinggenetic variation in $D$. cespitosa populations that colonized metal-contaminated and uncontaminated regions.

\section{MATERIALS AND METHODS}

\subsection{Molecular Analysis}

\subsubsection{Sampling and DNA Extraction}

Genetic materials were obtained from three regions located across the Northern Ontario and exhibiting various concentrations of metal contamination in the soil (Nkongolo et al., 2007). The Sudbury region includes Coniston, Falconbridge, Copper Cliff and Walden areas. The Cobalt region includes Cobalt-3, Cobal-4 and Cobalt-5. Little Current and Mississagi Lighthouse were used as references (Fig. 1). At each site 10\% of the population was sampled. Total genomic DNA was extracted from Deschampsia cespitosa plant leaves according to the CTAB extraction protocol, described in (Mehes et al., 2007; Nkongolo et al., 2005). At each region, at least three sites (replicates) were sampled.

\subsection{ISSR Analysis}

A total of 15 ISSR primers were pre-screened for polymorphism and reproducibility. Of these, five primers that produced strong and reproducible bands were selected for ISSR analysis. These included 17899B, UBC 818, UBC 827, UBC 835 and UBC 841. PCR amplification was carried out as described by (Nagaoka and Ogihara, 1997; Mehes et al., 2007) in a $25 \mu \mathrm{L}$ total volume containing a master mix of $11.4 \mu \mathrm{L}$ distilled water, $2.5 \mu \mathrm{L} \mathrm{MgSO}_{4}, 2.1 \mu \mathrm{L} 10 \mathrm{x}$ buffer $0.5 \mu \mathrm{L}$ of dNTPs (equal parts dTTP, dATP, dCTP, dGTP), $0.5 \mu \mathrm{L}$ of ISSR primer, a Taq mix of $3.475 \mu \mathrm{L}$ distilled water, $0.4 \mu \mathrm{L} 10 \mathrm{x}$ buffer and $0.125 \mu \mathrm{L}$ Taq polymerase (Applied Biosystems) and $4 \mu \mathrm{L}$ standardized DNA. Each primer contained a negative control of master mix and Taq mix without any DNA. All samples were covered with one drop of mineral oil to prevent evaporation and amplified with the Eppendorf Mastercycler gradient thermocycler. The program was set to a hot start of $5 \mathrm{~min}$ at $95^{\circ} \mathrm{C}$ followed by $2 \mathrm{~min}$ at $85^{\circ} \mathrm{C}$, then 42 cycles of $1.5 \mathrm{~min}$ at $95^{\circ} \mathrm{C}, 2 \mathrm{~min}$ at $55^{\circ} \mathrm{C}$ and one minute of $72^{\circ} \mathrm{C}$ after the addition of the Taq mix. A final extension of $7 \mathrm{~min}$ at $72^{\circ} \mathrm{C}$ after which samples were removed from thermocycler and placed in the $-20^{\circ} \mathrm{C}$ freezer until further analysis.

Amplified DNA products were separated for analysis on a $2 \%$ agarose gel and stained in ethidium bromide. Then, $5 \mu \mathrm{L}$ of $2 \times$ loading buffer were added to the PCR products and $10 \mu \mathrm{L}$ of this solution were loaded into the wells of the gel. The gel was run at $64 \mathrm{~V}$ for $120 \mathrm{~min}$, documented with the Bio-Rad ChemiDoc XRS system and analyzed with Image Lab Software.These agarose gels were visualized under UV light source, documented 
with the Bio-Rad ChemiDoc XRS system and analyzed for band presence or absence with the Discovery Series Quantity One 1D Analysis Software. The ISSR bands on each gel were scored as either present (1) or absent (0). These agarose gels were visualized under UV light source, documented with the Bio-Rad Chemi Doc XRS system and analyzed for band presence or absence with the Discovery Series Quantity One 1D Analysis Software. The resulting data matrix of the ISSR phenotype was analyzed using POPGENE software 11 (version 1.32) to estimate genetic diversity parameters. Among-region polymorphism data were compared using Tukey multiple comparison test after $\log _{10}$ transformation to achieve a normal distribution.

\subsection{Nuclear Microsatellite Analysis}

Detailed description of nuclear microsatellite analysis is described in a recent document (Gervais and Nkongolo, 2011). A total of 31 microsatellite primers, developed in several members of the Poaceae family, were screened for cross-species conservation in Deschampsia cespitosa. In total, 5 microsatellite primers from Elymus caninus (Sun et al., 1999), 7 from Avena sativa (Li et al., 2000), 3 from Triticum aestivum (Röder et al., 1995) and 17 from Hordeum vulgare (Liu et al., 1996; MacRitchie and Sun, 2004; Struss and Plieske, 1998) were screened for cross-species conservation in Deschampsiacespitosa. These microsatellites primers were selected based on the phylogenetic relationship between the species of origin and Deschampsia cespitosa, the polymorphic index of the alleles within their respective species and, in some cases, previous reports of cross-species conservation of the microsatellite locus (Gervais and Nkongolo, 2011).

Polymerase Chain Reactions (PCR) were carried out in $25 \mu \mathrm{L}$ volumes, each containing $1 \mathrm{X}$ reaction buffer, $1.5 \mathrm{mM} \mathrm{MgSO} 4,200 \mu \mathrm{M}$ of each dNTP, $0.2 \mu \mathrm{L}$ of forward and reverse primers, 0.625 units of TAQ polymerase and $20 \mathrm{ng}$ of template DNA. All 31 microsatellite primer pairs were initially screened for amplification by gradient PCR in a DNA thermal cycler (MJ research PTC-200 Peltier Thermal Cycler). The profile consisted of a hotstart at $95^{\circ} \mathrm{C}$ for $5 \mathrm{~min}$ and $85^{\circ} \mathrm{C}$ for $2 \mathrm{~min}$ followed by 42 cycles at a denaturing temperature of $95^{\circ} \mathrm{C}$ for $30 \mathrm{sec}$, an annealing temperature varying from 36 to $60^{\circ} \mathrm{C}$ for 90 sec and an elongation of $72^{\circ} \mathrm{C}$ for $30 \mathrm{sec}$, followed by a final extension of $7 \mathrm{~min}$ at $72^{\circ} \mathrm{C}$.

The PCR products were pre-screened for successful amplification. Three times Agarose Gel Loading Buffer was added to $10 \mu \mathrm{L}$ of each sample and loaded into a $1 \%$ agarose gel in $0.5 \times \mathrm{TBE}$. Gels were pre-stained with 4 $\mu \mathrm{L}$ of ethidium bromide and run at $3.14 \mathrm{~V} / \mathrm{cm}$ for approximately $90 \mathrm{~min}$ in $0.5 \times \mathrm{TBE}$. These agarose gels were visualized under UV light source, documented with the Bio-Rad ChemiDoc XRS system and analyzed with the Discovery Series Quantity One 1D Analysis Software. This screening process were performed to determine whether the PCR products were truly microsatellite loci, rather than random alleles.

The amplified products were thenresolved on a 0.4 $\mathrm{mm}$ denaturing polyacrylamide gel $[6 \% \quad(19: 1$ acrylamide/bisacrylamide), 8 M Urea, 1X TBE]. Seventy millilitres of Polyacrylamide Gel (PAGE) was degassed by a vacuum pump for $10 \mathrm{~min}$. Following this, $70 \mu \mathrm{L}$ of $0.25 \mathrm{mg} \mu \mathrm{L}^{-1}$ ammonium persulfate and $70 \mu \mathrm{L}$ of TEMED were added to the gel and gently swirled. The solution was cast in a 70 well Sequi-Gene GT Nucleic Acid Electrophoresis Glass Plates (Bio-Rad) and allowed to polymerize for an hour. This unit is composed of a notched plate, treated with $3 \mathrm{~mL}$ of Sigma Coat and a large square plate, treated with bind saline. Once polymerized, the gel was placed in the Electrophoresis Cell and preheated to $55^{\circ} \mathrm{C}$. During this time, $9 \mu \mathrm{L}$ of $3 X$ PAGE Loading Buffer (10N NaOH, 0.05\% $50 \mathrm{mg}$ $\mathrm{mL}^{-1}$ Xylene Cyanol, $0.05 \%$ of $50 \mathrm{mg} \mathrm{mL}^{-1}$ Bromophenol Blue, $0.5 \mathrm{M}$ EDTA, $1878 \mu \mathrm{L}$ of $95 \%$ Formamide) was directly added to the PCR tubes. The samples were then denatured in the Peltier Thermal Cycler for $10 \mathrm{~min}$ at $99^{\circ} \mathrm{C}$ and immediately placed on ice. Seven microliters of sample was loaded into each well and run at $55^{\circ} \mathrm{C}, 2$ $100 \mathrm{~V}, 90 \mathrm{~mA}$ and $73 \mathrm{~W}$ for approximately $120 \mathrm{~min}$ depending on the expected band size.

Following electrophoresis, the PCR products were stained with the Silver Sequence ${ }^{\mathrm{TM}}$ DNA Sequencing System by the Promega Corporation (2800 Woods Hollow Road, Madison, WI, 53711-5399, USA) according to the manufacturer's guidelines (Technical Manual No. D004). The plates were separated and the gel, which remained adhered to the large glass plate, was placed in $2 \mathrm{~L}$ of fix/stop solution $\left(1800 \mathrm{~mL} \mathrm{ddH_{2 }} \mathrm{O}, 200\right.$ $\mathrm{mL}$ glacial acetic acid) and gently mixed at $92 \mathrm{rpm}$ for 45 min or until the indicator dye had left. This was followed by three successive washes of two minutes each at $92 \mathrm{rpm}$ in $2 \mathrm{~L}$ of double distilled water. The gel was then transferred to the Silver Staining Solution (1 pkg Silver Nitrate, $3 \mathrm{~mL}$ of formaldehyde, in $2 \mathrm{~L} \mathrm{ddH}_{2} \mathrm{O}$ ) and allowed to stain at $70 \mathrm{rpm}$ for $30 \mathrm{~min}$. The gel was then quickly dipped in 2L of double distilled water and immediately placed in $1 \mathrm{~L}$ of pre-chilled Developer Solution (Sodium Carbonate, $3 \mathrm{~mL}$ formaldehyde, 400 $\mu \mathrm{L}$ aliquot of Sodium Thiosulfate). It was washed until 
the $10 \mathrm{bp}$ ladder was visible and then transferred to another 1 L of pre-chilled Developer Solution until all the alleles were visible. Developing was then ceased by the addition of $1 \mathrm{~L}$ Fixer Solution and washed at $92 \mathrm{rpm}$ for $5 \mathrm{~min}$. The gel was washed twice for $2 \mathrm{~min}$ at $92 \mathrm{rpm}$ in double distilled water. The plate was dried down, documented by the Bio-Rad GS-800 densitometer and analyzed with the Discovery Series Quantity One 1D Analysis Software. The gel was then placed in $2 \mathrm{~L}$ of $10 \%$ sodium hydroxide for $45 \mathrm{~min}$, then put in $2 \mathrm{~L}$ of distilled water for 2 min and finally transferred to chromatography paper and allowed to air dry overnight before scoring.

\subsection{Data Analysis}

The presence and absence of alleles yielded by the microsatellite primer pairs were scored as 1 or 0 , respectively in order to determine the polymorphism of each locus. Such designations were carried out with the quantity one software by establishing the alleles of interest and comparing them to the $10 \mathrm{bp}$ ladder which served as a marker system. The data was computed into the Popgene software, version 1.32 (Yeh and Boyle, 1997) and used to determine the intra-and interpopulation genetic diversity parameters such as number of alleles per locus, mean number of alleles across loci, percentage of polymorphic loci and Shannon's information index. In order to determine whether the observed allelic proportions met Hardy-Weinberg expectations, the populations were tested using an exact test (Guo and Thompson, 1992) by the computer program GENEPOP version 1.2. (Raymond and Rousset, 1995). HardyWeinberg Equilibrium deviations were further tested with heterozygote deficiency and excess alternative hypotheses. The Ewen-Watterson neutrality test was performed for each locus as well as a test for null alleles per loci (Dempster et al., 1977) by the Popgene software. Wright's $F$ statistics including inbreeding coefficients and fixation index (Weir and Cockerham, 1984) as well as gene flow were determined using Popgene.

\section{RESULTS AND DISCUSSION}

\subsection{ISSR Analysis}

Five of the primers screened produced amplifications ranging from 160 to $1300 \mathrm{bp}$ (Table 1). Figure 1 depicts PCR-amplified products using primer $17828 \mathrm{~B}$. There were no significant differences among populations within each region based on the levels of polymorphic loci. When the three regions were compared, the highest polymorphism was observed in samples from the Sudbury region (Coniston, Falconbridge, Copper Cliff,
Walden), with an average of $74 \%$ of polymorphism, followed by the control sites (Little Current and Mississagi Lighthouse) with $69 \%$. The lowest level of polymorphic loci of $46 \%$ on the average was observed in samples from the Cobalt region (Cobalt-3, Cobalt- 4 and Cobalt-5) which also has the highest accumulation of heavy metal (Table 2).

\subsection{SSR Analysis}

Table 3 describes the microsatellite primer pairs selected for analysis of $D$. cespitosa populations from the Northern Ontario region. Figure 2 depicts amplified products using primer pair HVM 65. Microsatellite scoring is often prone to error due to the presence of false alleles, also known as stutter bands, which are a result of polymerase slippage during replication (Dewoody et al., 2006). The stuttering patterns vary in magnitude and shape as well as across loci which can make interpreting particularly difficult in the case of adjacent-allele heterozygotes (Dewoody et al., 2006). As a result, in order to maintain consistency, scoring guidelines used in interpreting the electropherograms were based on the observations of Fernando et al. (2003). Firstly, since polymerase slippage is unidirectional, the resulting stutter bands are smaller in size than to their true alleles. Therefore, the largest allele was always recorded and scored as the true allele. Secondly, in cases were heterozygotes demonstrated alleles that differed by just a few repeats, the stutter bands of the larger allele would have been additively superimposed on the smaller allele. As such, the smaller alleles were recorded and scored only in instances were they demonstrated double the peak intensity of the larger allele. Also, in cases of heterozygotes characterized by alleles distant enough to eliminate possible superimposition, the smaller alleles tended to amplify more strongly than the larger allele. Finally, in instances were a split peak was observed, that is, two peaks one bp apart, the sum of the two peaks were recorded and scored as representing the true allele.

The development of microsatellite markers de novo is extremely expensive, labour intensive and time consuming (Peakall et al., 1998; Saha et al., 2006). Several studies have examined the possibility of crossspecies transferability of microsatellite primers pairs developed in closely related species and have reported the conservation of some loci across genera and sometimes even families (Saha et al., 2006). In the present study, several polymorphic microsatellite loci were identified in Deschampsia cespitosa using SSR primer pairs developed in Hordeum vulgare (barley) and Triticum aetivum (wheat). 


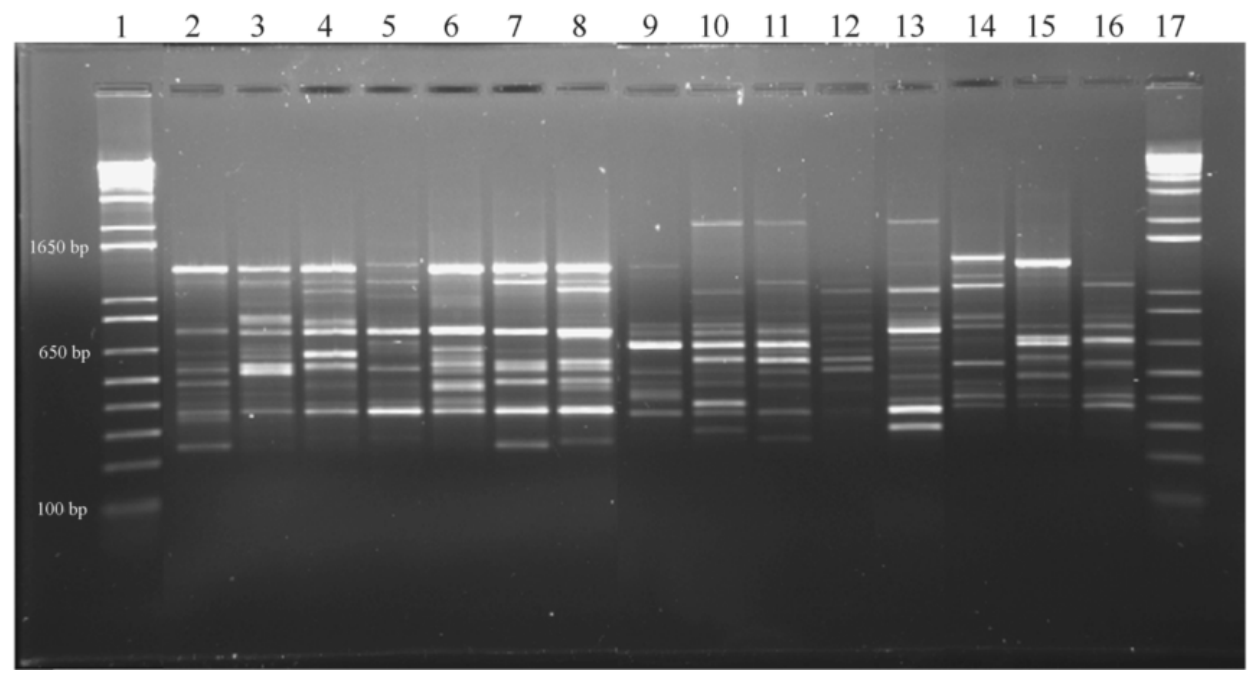

Fig. 1. ISSR amplification pattern with primer $17828 \mathrm{~B}$. Lanes 1 and 17 contain $1-\mathrm{kb}^{+}$DNA ladder, lanes 2 to 8 contain amplified products from Sudbury, lanes 9 to 13 amplified products from Cobalt, lane 14 amplified product from Little Current and lanes 15 and 16, amplified products from Mississagi Lighthouse

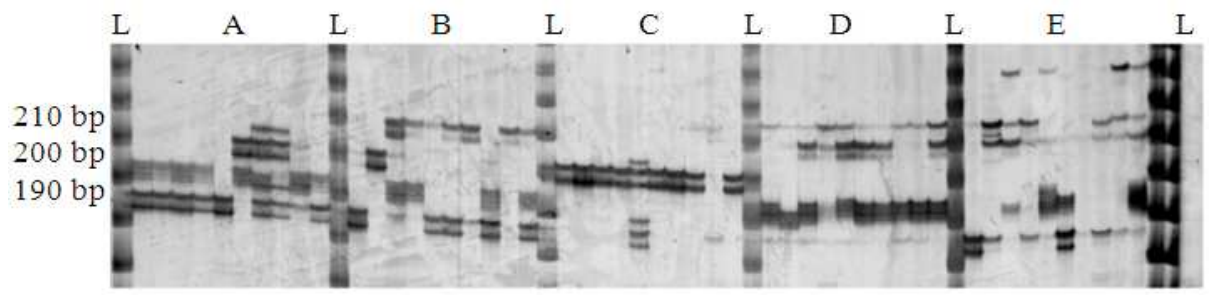

Fig. 2. HVM 65 primer pair PCR amplification products at optimal amplification conditions visualized on a $6 \%$ polyacrylamide gel. L represents 10 bp ladder; A section represents samples from Cobalt-3; B samples from Cobalt-4; C samples from Cobalt-5; D samples from Little Current; and E are samples from Mississagi Lighthouse.

Table 1. ISSR primers used to amplify genomic DNA from Deschampsia cespitosa samples

\begin{tabular}{lll}
\hline Primer identification & Nucleotide sequence $\left(5^{\prime} \rightarrow 3^{\prime}\right)$ & Fragment size range $(\mathrm{bp})$ \\
\hline ISSR 17898 B & CACACACACACAGT & $200-1300$ \\
UBC 818 & CACACACACACACACAG & $400-1100$ \\
UBC 827 & ACACACACACACACACG & $400-1000$ \\
UBC 835 & AGAGAGAGAGAGAGAGYC & $200-1000$ \\
UBC 841 & GAAGGAGAGAGAGAGAYC & $160-850$ \\
\hline
\end{tabular}

Table 2. Levels of polymorphisms within Deschampsia cespitosa populations from Northern Ontario generated with ISSR primers

\begin{tabular}{lllll}
\hline $\begin{array}{l}\text { Population } \\
\text { locations }\end{array}$ & $\begin{array}{l}\text { Soil metal } \\
\text { content }^{+}\end{array}$ & $\begin{array}{l}\text { Total no. } \\
\text { of bands }\end{array}$ & $\begin{array}{l}\text { No. of } \\
\text { polymorphic bands }\end{array}$ & $\begin{array}{l}\text { Polymorphic } \\
\text { bands }(\%) *\end{array}$ \\
\hline $\begin{array}{l}\text { Sudbury region } \\
\text { Cobalt region }\end{array}$ & Moderate to high & 70 & 52 & $74 \mathrm{a}$ \\
Little current & High to very high & 75 & 35 & $46 \mathrm{~b}$ \\
Mississagi lighthouse & Low & 66 & 46 & $70 \mathrm{a}$ \\
\hline
\end{tabular}

+ Source: Nkongolo et al. (2007). * Data with the same letter in the column are not statistically different based on the Tukey multiple comparison test $(\mathrm{P} \geq 0.05)$. 
Nkongolo, K.K. et al. / American Journal of Biochemistry and Biotechnology 10 (1): 69-80, 2014

Table 3. List of the microsatellite primer pairs selected for the analysis of Deschampsia cespitosa populations from Northern Ontario

\begin{tabular}{|c|c|c|c|c|c|c|}
\hline Species of origin & Locus & Primer Sequence $\left(5^{\prime} \rightarrow 3^{\prime}\right)$ & Repeat & Number of alleles & $\operatorname{Tm}\left({ }^{\circ} \mathrm{C}\right)$ & Expected size (bp) \\
\hline \multicolumn{7}{|l|}{ Triticum aestivum } \\
\hline & WMS6 & $\begin{array}{l}\text { cgtatcacctcctagctaaactag } \\
\text { agcettatcatgaccetacctt }\end{array}$ & $(\mathrm{GA})_{40}$ & 4 & 50 & 205 \\
\hline \multicolumn{7}{|l|}{ Hordeum vulgare } \\
\hline & HVM65 & $\begin{array}{l}\text { agacatccaaaaaatgaacca } \\
\text { tggtaacttgtcccccaaag }\end{array}$ & $(\mathrm{GA})_{10}$ & $5^{*}$ & $\mathrm{~T} 1$ & 129 \\
\hline & HVM3 & $\begin{array}{l}\text { acaccttcccaggacaatccattg } \\
\text { agcacgcagagcaccgaaaaagtc }\end{array}$ & $(\mathrm{AT})_{29}$ & $3 *$ & 55 & 188 \\
\hline & HVM5 & $\begin{array}{l}\text { aacgacgtcgecacacac } \\
\text { aggaacgaagggagtattaagcag }\end{array}$ & $(\mathrm{GT})_{6}(\mathrm{AT})_{16}$ & $4 * *$ & 55 & 202 \\
\hline & HVM7 & $\begin{array}{l}\text { atgtagcggaaaaaataccatcat } \\
\text { cctagctagttcgtgagctacctg }\end{array}$ & $(\mathrm{AT})_{7}$ & $2 * *$ & 55 & 174 \\
\hline & HVM20 & $\begin{array}{l}\text { ctccacgaatctctgcacaa } \\
\text { caccgcctcetctttcac }\end{array}$ & $(\mathrm{GA})_{19}$ & $5^{*}$ & $\mathrm{~T} 1$ & 151 \\
\hline
\end{tabular}

\footnotetext{
${ }^{*}:$ Number of alleles expected in the Avena species

${ }^{* *}:$ Number of alleles expected in the Elymus species
}

Only primer pairs HVM3, HVM5, HVM20, HVM65 and WMS6 successfully amplified a clear, reproducible, distinguishable band within an acceptable range of the expected size while demonstrating polymorphism. This represents only $14 \%$ of the microsatellite primer pairs screened for transferability within Deschampsia cespitosa.

Genetic diversity within each population, region and locus was assessed using standard descriptive statistics. The five polymorphic microsatellite markers detected a total of 40 alleles. The mean number of alleles per locus across populations was 2.1, 2, 7.3, 4.6 and 2.6 for locus HVM 3, HVM 5, HVM 20, HVM 65 and WMS 6 respectively. The mean number of alleles per populations across loci was 3 for Little Current, 3.2 for Mississagi Lighthouse and Walden, 3.6 for Falconbridge and Copper Cliff, 3.8 for Coniston and Cobalt-5, 4 for Cobalt-4 and 5.2 for Cobalt-3. At the population level, the observed mean heterozygosity $\left(\mathrm{H}_{\mathrm{O}}\right)$ and the expected mean heterozygosity $\left(\mathrm{H}_{\mathrm{E}}\right)$ ranged from 0.413 and 0.48 in the Mississagi Lighthouse population to 0.645 and 0.76 in the Cobalt- 3 population. At the regional level, the $\mathrm{H}_{\mathrm{O}}$ ranged from 0.44 for the Sudbury Region to 0.68 for the Cobalt region. Shannon Index varied from 0.74 for Mississagi Lighthouse region to 1.1. for the Cobalt region (Table 4).

Inbreeding is defined as the non-random uniting of gametes which results in a decrease of heterozygotes. The level of inbreeding within a population is determined by the inbreeding coefficient, $\mathrm{F}_{\mathrm{IS}}$, where -1 (all individuals heterozygous) $\leq \mathrm{F}_{\mathrm{IS}} \leq 1$ (no observed heterozygotes). The inbreeding coefficients $\left(\mathrm{F}_{\mathrm{IS}}\right)$ were determined for each population per loci based on the null hypothesis of no inbreeding represented as $F_{I S}=-1$. All nine populations exhibited a negative $F_{\text {IS }}$ value at loci HVM3, HVM5 and HVM20 indicating an excess of heterozygotes. Only Walden and Cobalt-3 populations presented negative $F_{I S}$ values at locus HVM65. Finally, six of the nine populations exhibited negative $F_{\text {IS }}$ values at the WMS6 locus. As a result, the overall inbreeding coefficient for $D$. cespitosa populations were -0.179 , $0.083,-0.071,-0.346,-0.19,-0.066,-0.118,-0.21$ and 0.174 for Coniston, Falconbridge, Copper Cliff, Walden, Cobalt-3, Cobalt-4, Cobalt-5, Little Current and Mississagi Lighthouse, respectively. At the regional level, the inbreeding varied from- 0.13 for the Cobalt region to- 0.21 for the Little Current region.

The fixation index $\left(\mathrm{F}_{\mathrm{ST})}\right.$ is a measure of the extent of genetic differentiation among populations due to genetic drift. Values can range from 0.0, indicating no differentiation, to 1.0 , indicating complete differentiation. However, because the observed maximum is usually much less than 1.0, Wright (1978) suggests an $\mathrm{F}_{\mathrm{ST}}$ interpretation of 0.0 to 0.05 as little genetic differentiation, 0.05 to 0.15 as moderate genetic differentiation, 0.15 to 0.25 as great genetic differentiation and values above 0.25 as very great genetic differentiation. The $\mathrm{F}_{\mathrm{ST}}$ values were 0.079 for HVM5 and 0.088 for HVM20, indicating moderate genetic differentiation. Locus HVM65 and locus WMS6 demonstrated great genetic differentiation with 0.219 and $0.224 \mathrm{~F}_{\mathrm{ST}}$ values, respectively. Finally, HVM3 locus represented a very great deal of genetic differentiation with an $\mathrm{F}_{\mathrm{ST}}$ value of 0.311 . 
Nkongolo, K.K. et al. / American Journal of Biochemistry and Biotechnology 10 (1): 69-80, 2014

Table 4. Metal content level and genetic diversity estimates for Deschampsia cespitosa populations

\begin{tabular}{|c|c|c|c|c|c|}
\hline \multirow[b]{2}{*}{ Regions } & \multirow[b]{2}{*}{ Soil metal content ${ }^{+}$} & \multicolumn{4}{|c|}{ Genetic parameters } \\
\hline & & $\mathrm{H}_{\mathrm{O}}$ & $\mathrm{H}_{\mathrm{E}}$ & I & $\mathrm{F}_{\text {IS }}$ \\
\hline Sudbury & Moderate to high & 0.44 & 0.54 & 0.94 & -0.17 \\
\hline Cobalt & High to very high & 0.68 & 0.60 & 1.10 & -0.13 \\
\hline Little Current & Low & 0.62 & 0.52 & 0.84 & -0.21 \\
\hline Mississagi Lighthouse & Low & 0.48 & 0.41 & 0.74 & -0.17 \\
\hline
\end{tabular}

+ Source: Nkongolo et al. (2007)

$\mathrm{H}_{\mathrm{O}}$, observed heterozygosity; $\mathrm{H}_{\mathrm{E}}$, expected heterozygosity; I, Shannon's information index; $\mathrm{F}_{\mathrm{IS}}$, inbreeding coefficient (Wright, 1978)

The $\mathrm{F}_{\mathrm{ST}}$ values were subsequently used to estimate the level of gene flow $\left(\mathrm{N}_{\mathrm{m}}\right.$ for each locus according to Nei (1987), where $\mathrm{N}_{\mathrm{m}}=0.25\left(1-\mathrm{F}_{\mathrm{ST}}\right) / \mathrm{F}_{\mathrm{ST}}$. The mean level of gene flow was 0.933 with individual $\mathrm{N}_{\mathrm{m}}$ values ranging from 0.5424 for the HVM65 locus to 2.347 for the HVM5 locus.

\subsection{Genetic Variation and Metal Contamination in Northern Ontario}

There are theoretical reasons for expecting the genetic variance of a life history character to increase when the population is challenged with a novel environment, an expectation that has been upheld empirically by numerous studies (Gervais and Nkongolo, 2011; Holloway et al., 1990; Service and Rose, 1985). If metal tolerance is controlled by many genes, as suggested by Von Frenkall-Insam and Hutchinson (1993) and Macnair (1993), it is very likely that allelic frequency in an outcrossing and perennial species like $D$. cespitosa will be maintained over time resulting in a neutral genetic variation (Gervais and Nkongolo, 2011).

Dechampsia cespitosa has shown a remarkable ability to colonize and dominate metal contaminated lands with great success. They have colonized over $1000 \mathrm{~s}$ of hectares of barren lands around Sudbury, following the constructions of the Super Stack in 1972 (Nkongolo et al., 2001). Detailed analysis of the four regions with microsatellite markers revealed the observed mean Heterozygosity $\left(\mathrm{H}_{\mathrm{O}}\right)$ and the expected mean Heterozygosity $\left(\mathrm{H}_{\mathrm{E}}\right)$ ranging from 0.413 and 0.48 in the Mississagi Lighthouse population to 0.645 and 0.76 in the Cobalt-3 region. In addition, genetic diversity measures based on Nei's and Shannon's index demonstrated a similar pattern with values ranging from 0.3920 and 0.8401 in Mississagi Lighthouse to 0.6130 and 1.2141 in Cobalt-3.

The Cobalt region contained high levels of arsenic, lead, zinc, cadmium and cobalt whereas the Mississagi Lighthouse and Little Current consistently grouped as the sites with the significantly least amount of metals (Nkongolo et al., 2007). Based on the nuclear microsatellite data, the level of genetic diversity does not decrease with increased metal contamination. For example, the lowest genetic diversity and population heterozygosity were observed in reference sites (Uncontaminated) while the highest in Cobalt-3 (the most contaminated site). These findings are consistent with earlier isozyme analysis described by Bush and Barrett (1993). The elevated levels of genetic diversity within these mining populations can be ascribed to number of selective, reproductive and demographic factors. Bourret et al. (2007) demonstrated that tolerance to the adverse environmental condition such as metal contamination increases genetic variation within the affected population.

Most of the Northern Ontario sites were mining areas well known for the severity of environmental degradation. Therefore it was expected that $D$. cespitosa and other heavy metal tolerant herbaceous species are likely to exhibit genetic changes compared to conifer. Although long exposure to metal did not result in detectable allelic changes.

On the other hand, significant decrease of genetic diversity caused by long term exposure to metal was detected using ISSR markers. Other studies have previously demonstrated similar phenomenon using different genetic markers systems (Lopes et al., 2004; Van Straalen and Timmermans, 2002). It is possible that those differences are related to ecotypic adaptation rather than the results of differences in allelic frequency caused by metal contamination. The regions of the genome targeted by each molecular marker system can also result in different outcome for the genetic variation levels.

\subsection{Differences between Inter-Simple Sequence Repeat (ISSR) and Simple Sequence Repeat (SSR) or Microsatellite Markers}

\subsubsection{ISSR}

The ISSR marker system is based on the use of 15-20 bp primers designed to be complimentary to SSR 
(microsatellite) sequences found throughout eukaryotic genomes. The ISSR markers are dominant. This PCR based technique involves the amplification of DNA segments present between two identical microsatellites that are oriented in opposite directions (Reddy et al., 2002). In other words, microsatellite repeats target multiple genomic loci to amplify their inter-SSR sequences of different sizes. Although the microsatellite repeat utilized as the primer can by di-, tri-, tetra- or penta-nucleotide repeats, those with (AG), (GA), (CT), (TC), (AC), (CA) repeats have been shown to reveal higher polymorphism than other di-, tri- or tetranucleotides (Reddy et al., 2002).

Overall, these markers are based on the presence of microsatellites throughout the entire genome therefore describing the DNA characteristics of an individual over several chromosomal loci (Bornet and Branchard, 2004; Hundsdoerfer et al., 2005). As a result, no two amplification patterns will be identical, although those originating from the same species will be more similar than those from more distantly related species. The characteristic of this multi-locus marker system allows it to be useful in areas such as identifying individualspecific differences, inter-species genomic fingerprinting, genetic diversity, phylogenetic inferences, gene tagging, genome mapping and evolutionary biology (Bornet and Branchard, 2004; Godwin et al., 1997; Panda et al., 2003; Reddy et al., 2002; Zhang et al., 2013). For example, previous studies carried out on finger millet, chrysanthemum, sorghum, maize, Pseudotsuga menzeisii and Cryptomeria japonica have reported the successful use of this method in determining genetic diversity and genomic origins of these species (Godwin et al., 1997). In addition, studies suggest that this method can be used to confirm the presence and evaluate the distribution of certain microsatellite repeats within different genomes (Zietkiewicz et al., 1994).

There are a number of advantages associated with the ISSR multi-locus technique. Firstly, ISSRs are universal in the sense that microsatellite repeats are found in every eukaryotic genome studied to date. Secondly, unlike their RAPD counterparts, ISSR have high reproducibility. This is most likely due to the longer lengths of the primers which permit the use of higher annealing temperatures which in turn, reduces non-specific binding and results in higher stringency (Bornet and Branchard, 2004; Qian et al., 2001). Furthermore, contrary to microsatellites, amplification does not require prior knowledge of the DNA sequence. ISSRs are quick and easy to handle and reveal multi-locus, highly polymorphic patterns. Finally, because each band corresponds to a DNA sequence delimited by two inverted microsatellites, the amplified products, usually 200$2000 \mathrm{bp}$ long, are detectable by both agarose and polyacrylamide gel electrophoresis (Reddy et al., 2002).

\subsubsection{SSR Markers}

Microsatellites are single locus, co-dominant, Mendelian inherited markers, which are highly polymorphic (Gaitán-Solís et al., 2002; Gupta et al., 1996). The basis for this polymorphism is the variation in the number of repeats at a specified locus (Gupta et al., 1996). Such variation is attributed to the high mutation rate of microsatellites estimated to be four orders of magnitude greater than non-SSR loci (Peakall et al., 1998). In eukaryotes, the rate of mutation varies between species, individuals and loci, ranging from $10^{-7}$ to $10^{-3}$ per locus per generation (Ellegren, 2000). As a result, microsatellites are very often multiallelic as supported by several studies including those on the SAT1 locus in soybean consisting of 26 alleles (Rongwen et al., 1995), the GMS046 locus in barley with 15 alleles (Struss and Plieske, 1998), the BM188 in Phaseolus vulgaris with 14 alleles (Gaitán-Solís et al., 2002), the UAPgCT3 locus in Piceamariana with 11 alleles (Dobrzeniecka et al., 2011) to mention a few. Such hypervariability means that microsatellites have the potential to show polymorphism in species otherwise characterized by low levels of genetic diversity. As a result, microsatellites are considered as ideal markers for forensic identification, paternity analysis, gene mapping, plant breeding, conservation biology and population genetics (Buschiazzo and Gemmell, 2006; Gupta et al., 1996; Kumar and Sharma, 2011; Mehes et al., 2007; 2009; Hamza et al., 2013; Peakall et al., 1998; Simpson et al., 2013).

The mutation mechanism of these particular regions may be the result of slipped strand mispairing or unequal crossing-over. During DNA replication, the parental and nascent strands may dissociate periodically, also known as replication slippage. During subsequent reassociation, there is a potential for misalignment because of the repetitive nature of the sequence. The outcome of an out of register realignment could be either a gain or a loss of repeat units resulting in a series of alleles with size differences (Li et al., 2000). The second proposed mechanism is the result of non-reciprocal recombination in which there is an unequal exchange of microsatellite sequence. One explanatory model suggest gene conversion due to recombination involving two fourstranded structure called Holliday junctions whereas the other suggests that the nascent strands are separated from 
the parental template and annealed out of frame to one another (Szostak et al., 1983; Richard and Pâques, 2000). Many factors, including repeat number, sequence class, motif length and location, affect microsatellite evolution. (Schlötterer, 2000) For example, long perfect repeats tend to mutate faster than shorter ones because highly repeated motifs increase the instability of the replication machinery. Also, as the motif length increases, the mutation rate decreases, therefore dinucleotides have the highest mutation rate followed by tri-, tetra- and pentanucleotides (Buschiazzo and Gemmel, 2006).

Microsatellite analysis is more variable and reliable than isozymes and dominant molecular markers used in other studies (Buschiazzo and Gemmell, 2006). In fact microsatellite markers are, hypervariable and abundant in the majority of genomes. They are characterized by a Mendelian mode of inheritance, co-dominant nature, high reproducibility and easy application. They have the potential to show polymorphism in species otherwise characterized by low levels of genetic diversity (Gaitán-Solís et al., 2002; Jones et al., 2001; Prasad et al., 2000). It should be pointed out that chloroplast microsatellite analysis has been also performed and no difference in genetic variation among metal contaminated and uncontaminated regions were detected (Gervais and Nkongolo, 2011).

The primary disadvantage of microsatellite markers is that the development of these markers is labour intensive and costly. DNA sequence knowledge is required to design appropriate primers pairs, therefore the development and application of microsatellites in plants has been mostly restricted to a few of our most important agricultural crops (Peakall et al., 1998). For example, the de novo development and application of microsatellite markers for crops such as barley (Li et al., 2000), oat wheat (Röder et al., 1995) and rye (Saal and Wricke, 1999) has been frequently reported.

Comparative genomics performed on wheat, maize, rice and other various grass species has revealed remarkable conservation of gene content and gene order (Gale and Devos, 1998). The relatively high sequence similarity among members of the Poaceae family, suggests the high probability of transferable microsatellite primer pairs across genera. Cross-species transferability of microsatellites mainly depends on the extent to which the flanking regions are conserved between related species as well as the stability of the microsatellite loci over time. In recent years, numerous studies have reported the ability of microsatellite transferability across multiple species including rye, wheat and triticale (Kuleung et al., 2004), soybean
(Peakall et al., 1998), tall fescue (Saha et al., 2006), bean (Gaitán-Solís et al., 2002), oat (Li et al., 2000) and Medicago truncatula (Gutierrez et al., 2005).

\section{CONCLUSION}

Although several reports have highlighted a higher level of genetic variation generated with SSR primers compared to ISSR primers (Mehes et al., 2007 and 2009; Kumar and Sharma, 2011; Hamza et al., 2013) the present study revealed that ISSR markers were useful in differentiating $D$. cespitosa populations growing in regions with different levels of heavy metals. The levels of polymorphic loci generated with ISSR and of observed heterozygosity obtained with SSR weremoderate to high. But SSR analysis did not detect any allele changes. Considering that both ISSR and SSR are neutral molecular markers,analysis of expression of genes or gene products associated with metal tolerance can provide insights information on molecular changes resulting from metal accumulation.

\section{ACKNOWLEDGEMENT}

The researchers thank the Natural Sciences and Engineering Research Council of Canada (NSERC), Vale (Sudbury) and Xstrata (Sudbury) for financial support.

\section{REFERENCES}

Akkaya, S.M., A.A. Bhagwat and P.B. Cregan, 1992. Length polymorphism of simple-sequence repeat DNA in soybean. Genetics,132: 1131-1139.

Bell, C.J. and J.H. Ecker, 1994. Assignment of 30 microsatellite loci to the linkage map of Arabidopsis. Genomics, 19: 137-144. DOI: 10.1006/geno.1994.1023

Bornet, B. and M. Branchard, 2004. Use of ISSR fingerprints to detect microsatellites and genetic diversity in several related Brassica taxa and Arabidopsis thaliana. Hereditas, 140: 246-248. DOI: 10.1111/j.1601-5223.2004.01737.x

Bourret, V., P. Couture, P.G.C. Campbell and L. Bernatchez, 2007. Evolutionary ecotoxicology of wild perch (Perca flavescens) populations chronically exposed to a polymetallic gradient. Aquat. Toxicol., 86: 76-90. DOI: 10.1016/j.aquatox.2007.10.003 
Buschiazzo, E. and N.J. Gemmell, 2006. The rise, fall and renaissance of microsatellites in eukaryotic genomes. BioEssays, 28: 1040-1050. DOI: 10.1002/bies. 20470

Bush, E.J. and S.C.H. Barrett, 1993. Genetics of mine invasions by Deschampsia cespitosa (Poaceae)"Can. J. Botany, 71: 1336-1348. DOI: 10.1139/b93-159

Dempster, A.P., N.M. Laird and D.B. Rubin, 1977. Maximum likelihood from incomplete data via the EM algorithm. J. Royal Stat. Society Series B, 39: 1-38. DOI: $10.2307 / 2984875$

Deng, J., B. Liao, M. Ye, D. Deng and W. Shu, 2007. The effects of heavy metal pollution on the genetic diversity in zinc/cadmium hyperaccumulator Sedum alfredii populations. Plant Soil, 297: 83-92. DOI: 10.1007/s11104-007-9322-5

Dewoody, J., J.D. Nason and V.D. Hipkins, 2006. Mitigating scoring errors in microsatellite data from wild populations. Mol. Ecol. Notes, 6: 951-957. DOI: 10.1111/j.1471-8286.2006.01449.x

Dobrzeniecka, S., K.K. Nkongolo, P. Michael, M. Mehes-Smith and P. Beckett, 2011. Genetic analysis of black spruce (Picea mariana) populations from dry and wetareas of a metal-contaminated region in ontario (Canada). Water Air Soil Poll., 215: 117125. DOI: $10.1007 / \mathrm{s} 11270-010-0463-4$

Ellegren, H., 2000. Microsatellite mutations in the germline: Implications for evolutionary inference. Trends Genet., 16: 551-558. DOI: 10.1016/S01689525(00)02139-9

Fernando, P., T.N.C. Vidya, C. Rajapakse, A. Dangolla and D.J. Melnick, 2003. Reliable noninvasive genotyping: Fantasy or reality. J. Hered, 94: 115123. DOI: $10.1093 /$ jhered/esg022

Gaitán-Solís, E., Duque, M.C., K.J. Edwards and J. Tohme, 2002. Microsatellite repeats in common bean (Phaseolus vulgaris): Isolation, characterization and cross-species amplification in Phaseolus ssp. Crop Sci., 42: 2128-2136. DOI: 10.2135/cropsci2002.2128

Gale, M.D. and K.M. Devos, 1998. Comparative genetics in the grasses. Proc. Nat. Acad. Sci. USA., 95: 1971-1974. DOI: 10.1073/pnas.95.5.1971

Gervais, S. and K. Nkongolo, 2011. Effect of Metal Contamination on the Genetic Diversity of Deschampsia cespitosa Populations from Northern Ontario: An Application of ISSR and Microsatellite Markers. In: Relevant Perspectives in Global Environmental Change, Agboola J. (Ed.), pp: 115-138.
Godwin, I.D., E.A.B. Aitken and L.W. Smith, 1997. Application of Inter Simple Sequence Repeat (ISSR) markers to plant genetics. Electrophoresis, 18: 15241528. DOI: $10.1002 /$ elps. 1150180906

Guo, S.W. and E.A. Thompson, 1992. Performing the exact Hardy-Weinberg proportion for multiple alleles. Biometrics, 48: 361-372. DOI: $10.2307 / 2532296$

Gupta, P.K., H.S. Baylan, P.C. Sharma and B. Ramesh, 1996. Microsatellites in plants: A new class of molecular markers. Curr. Sci. India, 70: 45-54.

Gutierrez, M.V., M.C. Vaz, T. Patto, J.I. Huguet and M.T. Cubero et al., 2005. Cross-species amplification of Medicago truncatula microsatellites across three major pulse crops. Theor. Appl. Genet., 110: 1210-1217. DOI: 10.1007/s00122-005-1951-6

Hamza, H., M.A.B. Abederrahim, M. Elbekkay and A. Ferchichi, 2013. Comparison of the effectiveness of ISSR and SSR markers in determination of date palm (Phoenix dactylifera L.) agronomic traits. Aust. J. Crop Sci., 7: 763-769.

Holloway, G.J., S.R. Povey and R.M. Sibly, 1990. The effect of new environment on adapted genetic architecture. Heredity, 64: 323-330. DOI: 10.1038/hdy.1990.40

Hundsdoerfer, A.K., I.J. Kitching and M. Wink, 2005. The phylogeny of Hyles euphorbiae complex (Lepidoptera: Sphingidae): Molecular evidence for sequence data and ISSR-PCR fingerprints. Org. Divers. Evol., 5: 173-198. DOI: 10.1016/j.ode.2004.11.012

Jones, E.S., M.P. Dupal, R. Kölliker, M.C. Drayton and J.W. Forster, 2001. Development and characterisation of Simple Sequence Repeat (SSR) markers for perennial ryegrass (Lolium perenne L.). Theor. Applied Genet., 102: 405-415. DOI: 10.1007/s001220051661

Kuleung, C., P.S. Baenziger and I. Dweikat, 2004. Transferability of SSR markers among wheat, rye and triticale. Theor. Applied Genet., 108: 11471150. DOI: 10.1007/s00122-003-1532-5

Kumar, V. and S.N. Sharma, 2011. Comparative potential of phenotypic, ISSR and SSR markers for characterization of sesame (Sesam umindicum L.) varieties from India. J. Crop SciBiotechnol., 14: 163-171. DOI: 10.1007/s12892-010-0102-z

Li, C.D., B.G. Rossnagel and G.J. Scoles, 2000. The development of oat microsatellite markers and their use in identifying relationships among Avena species and oat cultivars. Theor. Applied Genet., 101: 1259-1268. DOI: 10.1007/s001220051605 
Liu, Z.W., R.M. Biyashev and M.A. SaghaiMaroof, 1996. Development of simple sequence repeat DNA markers and their integration into a barley linkage map. Theor. Applied Genet., 93: 869-876. DOI: 10.1007/BF00224088

Lopes, I., D.J. Baird and R. Ribeiro, 2004. Genetic determination of tolerance to lethal and sublethal copper concentrations in field populations of Daphnia longispina. Arch. Environ. Contam. Toxicol., 46: 43-51. DOI: 10.1007/s00244-0032143-5

MacNair, M.R., 1993. The genetics of metal tolerance in vascular plants. New Phytol., 124: 541-559. DOI: 10.1111/j.1469-8137.1993.tb03846.x

MacRitchie, D. and G. Sun, 2004. Evaluating the potential of barley and wheat microsatellite markers or genetic analysis of Elymus trachycaulus complex species. Theor. Applied Genet., 108: 720-724. DOI: 10.1007/s00122-003-1472-0

Mehes, M., K.K. Nkongolo and P. Michael, 2009. Assessing genetic diversity and structure of fragmented populations of eastern white pine (Pinus strobus) and western white pine (P. monticola) for conservation management. J. Plant Ecol., 2: 143151. DOI: $10.1093 /$ jpe/rtp016

Mehes, M.S., K.K. Nkongolo and P. Michael, 2007. Genetic analysis of Pinus strobus and Pinus monticola populations from Canada using ISSR and RAPD markers: Development of genome-specific SCAR markers. Plant Syst. Evol., 267: 47-63. DOI: 10.1007/s00606-007-0534-1

Mengoni, A., C. Gonnelli, F. Galardi, R. Gabbrielli and M. Bazzicalupo, 2000. Genetic diversity and heavy metal tolerance in populations of Silene paradoxa $\mathrm{L}$. (Caryophyllaceae): A random amplified polymorphic DNA analysis. Mol. Ecol., 9: 13191324. DOI: 10.1046/j.1365-294x.2000.01011.x

Mosseler, A., K.N. Egger and G.A. Hughes, 1992. Low levels of genetic diversity in red pine confirmed by random amplified polymorphic DNA markers. Can. J. Forest. Res., 22: 13321337. DOI: $10.1139 / \mathrm{x} 92-177$

Nagaoka, T. and Y. Ogihara, 1997. Applicability of inter-simple sequence repeat polymorphisms in wheat for use as DNA markers in comparison to RFLP and RAPD markers. Theor. Applied Genet., 94: 597-602. DOI: $10.1007 / \mathrm{s} 001220050456$

Nei, M., 1987. Molecular population genetics and Evolution. 1st Edn., Columbia University Press, New York.
Nkongolo, K.K., P. Michael and T. Demers, 2005. Application of ISSR, RAPD and cytological markers to the certification of Picea mariana, $P$. glauca and $P$. engelmannii trees and their putative hybrids. Genome, 48: 302-311. DOI: 10.1139/g04-118

Nkongolo, K.K., A. Deck and P. Michael, 2001. Molecular and cytological analyses of Deschampsia cespitosa populations from Northern Ontario (Canada). Genome, 44: 818825. DOI: $10.1139 / \mathrm{g} 01-063$

Nkongolo, K.K., M. Mehes, A. Deck and P. Michael, 2007. Metal content in soil and genetic variation in Deschampsia cespitosa populations from NorthernOntario (Canada): Application of ISSR markers. Eur. J. Genet. Mol.

Panda, S., J.P. Martin and I. Aguinagalde, 2003. Chloroplast and nuclear DNA studies in a few members of the Brassica oleracea L. group using PCR-RFLP and ISSR-PCR markers: A population genetic analysis. Theor. Applied Genet., 106: 1122-1128. DOI: 10.1007/s00122-002-1134-7

Peakall, R., S. Gilmore, W. Keys, M. Morgante and A. Rafalski, 1998. Cross-species amplification of soybean (Glycine max) Simple Sequence Repeats (SSRs) within the genus and other legume genera: Implications for the transferability of SSRs in plants. Mol. Biol. Evol., 15: 1275-1287. DOI: 10.1093/oxfordjournals.molbev.a025856

Prasad, M., R.K. Varshney, K.J. Roy and H.S. Balyan, 2000. The use of microsatellites for detecting DNA polymorphism, genotype identification and genetic diversity in wheat. Theor. Applied Genet., 100: 584-592. DOI: 10.1007/s001220050077

Qian, W., S. Ge and D.Y. Hong, 2001. Genetic variation within and among populations of a wild rice Oryza granulate from China detected by RAPD and ISSR. Theor. Applied Genet., 102: 440-449. DOI: $10.1007 / \mathrm{s} 001220051665$

Raymond, M. and F. Rousset, 1995. GENEPOP (Version 1.2): A population genetics software for exact tests and ecumenicism. J. Hered, 86: 248-249.

Reddy, M.P., N. Sarla and E.A. Siddiq, 2002. Inter Simple Sequence Repeat (ISSR) polymorphism and its application in plant breeding. Euphytica, 128: 9-17. DOI: 10.1023/A:1020691618797

Richard, G. and F. Pâques, 2000. Mini-and microsatellite expansions: The recombination connection. EMBO Rep., 1: 122-126. DOI: 10.1093/embo-reports/kvd031 
Röder, M.S., J. Plaschke, S.U. König, A. Börner and M.E. Sorrells et al., 1995. Abundance, variability and chromosomal location of microsatellites in wheat. Mol. Gen. Genet., 246: 327-333. DOI: 10.1007/BF00288605

Rongwen, J., M.S. Akkaya, A.A. Bhagwat, U. Lavi and P.B. Cregan, 1995. The use of microsatellite DNA markers for soybean genotype identification. Theor. Applied Genet., 90: 43-48. DOI: 10.1007/BF00220994

Saal, B. and G. Wricke, 1999. Development of simple sequence repeat markers in rye. Genome, 42: 964972. DOI: $10.1139 /$ gen-42-5-964

Saha, M.C., J.D. Cooper, M.A. RoufMian, K. Chekhovskiy and G.D. May, 2006. Tall fescue genomic SSR markers: Development and transferability across multiple grass species. Theor. Applied Genet., 113: 1449-1458. DOI: 10.1007/s00122-006-0391-2

Schlötterer, C., 2000. Evolutionary dynamics of microsatellite DNA. Chromosoma, 109: 365-371. DOI: $10.1007 / \mathrm{s} 004120000089$

Service, P.M. and M.R. Rose, 1985. Genetic covariance among life-history components: The effect of novel environments. Evolution, 39: 943-945. DOI: $10.2307 / 2408694$

Simpson, M.S., P.M. Wilken, M.P.A. Coetzee and B.D. Wingfield, 2013. Analysis of microsatellite markers in the genome of the plant pathogen Ceratocystis fimbriata. Fungal Biol., 117: 545-555. DOI: 10.1016/j.funbio.2013.06.004

Struss, D. and J. Plieske, 1998. The use of microsatellite markers for the detection of genetic diversity in barley populations. Theor. Applied Genet., 97: 308315. DOI: $10.1007 / \mathrm{s} 001220050900$

Sun, G.L., O. Diaz, B. Salomon and R. von Bothmer, 1999. Genetic diversity in Elymus caninusas revealed by isozyme, RAPD and microsatellite markers. Genome, 42: 420-431. DOI: $10.1139 /$ gen-42-3-420
Szostak, J.W., T.L. Orr-Weaver, R.J. Rothstein and F.W. Stahl, 1983. The double-strand break repair model for recombination. Cell, 33: 25-35. DOI: 10.1016/0092-8674(83)90331-8

Van Straalen, N.M. and M.J.T.N. Timmermans, 2002. Genetic variation in toxicant-stressed populations: An evaluation of the "genetic erosion" hypothesis. Human Ecol. Risk Assess., 8: 983-1002.

Von Frenkall-Insam, B.A.K. and T.C. Hutchinson, 1993. Occurrence of heavy metal tolerance and cotolerance in Deschampsia cespitosa (L.) Beauv. from European and Canadian populations. New Phyt., 125: 555-564.

Weir, B.S. and C.C. Cockerman, 1984. Estimating Fstatistics for the analysis of population structure. Evolution, 38: 1358-1370.

Wright, S., 1978. Evolution and the genetics of populations: Variability within and among natural populations. 1st Edn., University of Chicago Press, Chicago.

$\mathrm{Wu}$, K.S. and S.D. Tanksley, 1993. Abundance, polymorphism and genetic mapping of microsatellites in rice. Mol. Gen. Genet., 241: 225235. DOI: $10.1007 / \mathrm{BF} 00280220$

Yeh, F.C. and T.J.B. Boyle, 1997. Population genetic analysis of co-dominant and dominat markers and quantitative traits. Bel. J. Bot., 129: 157.

Zhang, L., H.G. Zhang and L. Xf, 2013. Analysis of genetic diversity in Larix gmelinii (Pinaceae) with RAPD and ISSR markers. Genet. Mol. Res., 12: 196-207. PMID: 23408406

Zietkiewicz, E., A. Rafalski and D. Labuda, 1994. Genome fingerprinting by Simple Sequence Repeat (SSR)-anchored polymerase chain reaction amplification. Genomics, 20: 176-183. DOI: 10.1006/geno.1994.1151 